\title{
LUNG WATER ESTIMATION USING AN EXTERNAL SENSING CATHETER
}

\author{
J.C. Kay and W.H. NobLE
}

Investigation of Patients often fails to detect subclinical oedema until hypoxia and respiratory acidosis have occurred. Early detection of pulmonary oedema would hasten and improve therapy, possibly preventing these complications and obviating the need for artificial ventilation.

Radiologists have used radiographs to detect pulmonary oedema but quantitation, although potentially possible, is subject to great uncertainty. ${ }^{1}$ To differentiate between pulmonary oedema and pulmonary congestion by radiography requires ideal conditions, an unlikely occurrence in an Intensive Care Unit (ICU) ${ }^{2}$

Other investigators have quantitated pulmonary extravascular water volume (PEWV) using double indicator dilution techniques. Chinard ${ }^{3}$ first demonstrated this technique using tritiated water as the diffusible indicator and T-1824 Evan's Blue as the intravascular indicator. Other intravascular indicators have been used: indocycanine green dye, chromiun tagged red cells and albumin ${ }^{131} I^{4-6}$. These indicators have several disadvantages. These include the difficulties of handling radio-active materials, the need for costly analysis equipment, blood loss of about $50 \mathrm{ml}$ per determination and limited repeatability due to radiation build-up. However, the major disadvantage is that the tritiated water technique only detects 60 per cent to 70 per cent of the water that can be found using a post-mortem weighing technique. ${ }^{7}$

To overcome these problems, investigators have searched for new indicators. Pearce and Beazell ${ }^{8}$ suggested the use of heat as a diffusible indicator. Noble and Severinghaus ${ }^{7}$ used 3 per cent sodium chloride at room temperature. In this case heat acts as a non-molecular diffusible indicator and the sodium ions remain within the vessel to produce a change in blood electrical conductivity. This technique measures cardiac output $(\dot{Q})$ and the extravascular thermal volume of the lung $\left(\operatorname{ETV}_{L}\right)$, a value that has correlated well with post-mortem measurements of PEWV. ${ }^{7.9}$ We used a special sensing catheter with transducers at the distal end but within the lumen of the catheter to detect blood conductivity and temperature changes. The catheter was inserted through the femoral artery until it was just distal to the aortic valve. Blood withdrawal is necessary to record the temperature and conductivity dilution curves. Anderson ${ }^{10}$ and Dunegan ${ }^{11}$ have used the ETV $V_{L}$ technique in dogs and described a sensing catheter that required no blood withdrawal.

We found the $\operatorname{ETV}_{\mathrm{L}}$ technique to be accurate in following the time course of

J.C. Kay, A.I.M.L.T.(ENG.), Department of Anaesthesia, St. Michael's Hospital and University of Toronto, Toronto, Ontario.

W.H. Noble, M.D., F.R.C.P.(C), Associate Professor, Department of Anaesthesia, University of Toronto, St. Michael's Hospital, Toronto, Ontario. 

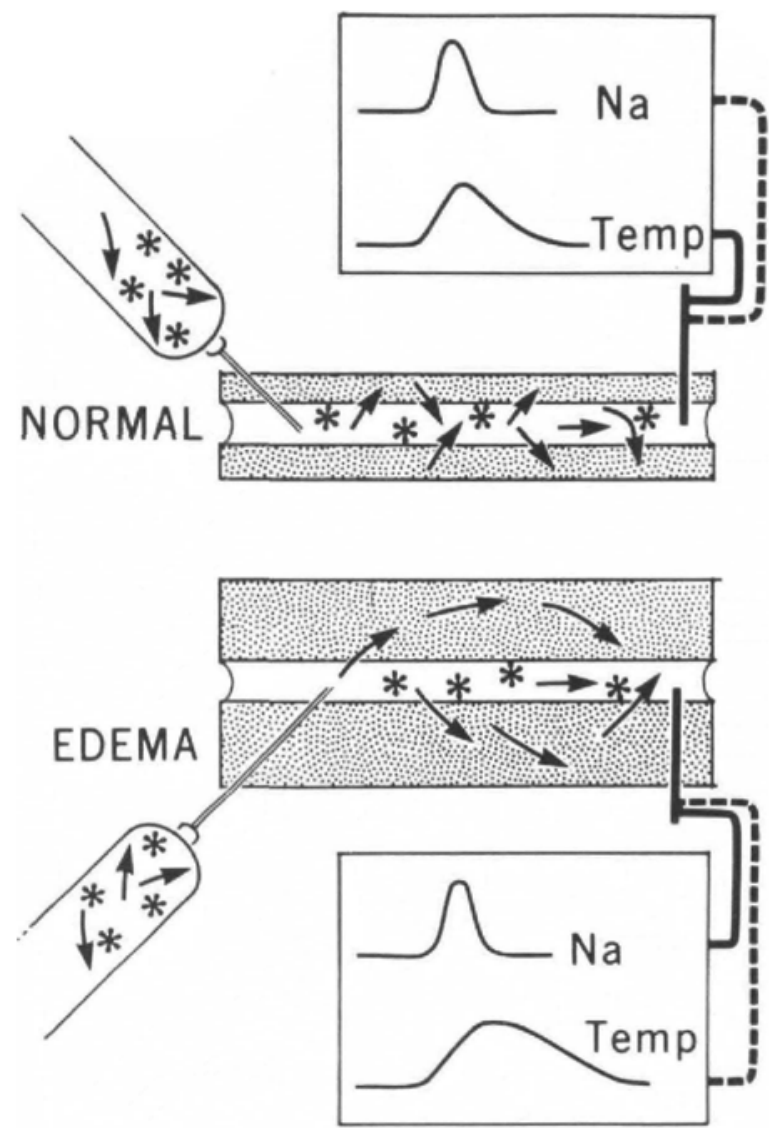

Figune 1. Principles of the ETV $V_{\mathrm{r}}$ method. Schematic drawing of normal and oedematous states. Three per cent sodium chloride is injected by a syringe into the pulmonary artery and detection of calories $(\uparrow)$ and sodium ions $\left({ }^{\circ}\right)$ is made in the aorta. Note the temperature curve is prolonged in the oedematous state.

pulmonary oedema in a number of dog studies ${ }^{2,7,9,12}$ and in view of this we decided to use the technique in human patients. To emulate our dog technique in patients a catheter was manufactured commercially, but because of its relatively large size it proved troublesome to pass along the aorta. The conductivity electrodes also reduce the internal diameter so that blood withdrawal and flushing are difficult. We constructed an external sensing catheter that will attach to the hub of any standard arterial catheter. This eliminates the insertion of the sensing catheter into the artery and allows blood withdrawal and flushing.

This technique offers the advantages of monitoring $\dot{Q}$ as well as $E T V_{L}$, virtually unlimited repeatability, relatively uncomplicated instrumentation, and no blood loss. It has the potential for revealing sub-clinical oedema, differentiating between congestion and pulmonary oedema, and determining the efficacy of various types of therapy.

The experiments reported here were done to evaluate the accuracy and reliability of the external catheter in monitoring $\mathrm{ETV}_{\mathrm{L}}$ and $\dot{Q}$ by comparison with the internal 
sensing catheter. Comparisons were made in normal dogs and in dogs with gross pulmonary oedema.

\section{Principle of The Method}

Figure 1 illustrates the principle of the method. In practice the injection site is the pulmonary artery and the detection site a point distal to the aortic valve. When 3 per cent sodium chloride at room temperature is injected, calories, which are non-molecular and not bound to any of the blood components, cross the vessel wall and move into the extravascular tissues and fluid. This temperature change is reversible and the path of the extravascular indicator will depend mainly on the quantity of fluid around the vessel. In oedema, because of the larger volume of distribution, the calories have a longer pathway compared to the normal vessel, resulting in a skewed thermal curve with a longer mean transit time. The sodium ions, however, remain within the vessel and their transit time will be unaffected by the oedema. Therefore, the difference in transit time $(\Delta t)$ between calories and sodium ions will be longer in the vessel surrounded by water.

\section{Calculation of Thermodilution Cardiac Output:}

Cardiac output is calculated using the formula

$$
\dot{Q}_{\mathrm{T}}=\frac{\left(\mathrm{V}_{\mathrm{T}}-\mathrm{V}_{\mathrm{I}}\right) \mathrm{D}_{\mathrm{I}} \mathrm{S}_{\mathrm{I}} \Delta \mathrm{T}_{\mathrm{I}}}{\mathrm{D}_{\mathrm{B}} \mathrm{S}_{\mathrm{B}} \int_{0}^{\infty} \mathrm{T}_{\mathrm{B}} \mathrm{t}_{\mathrm{B}} \mathrm{d}_{\mathrm{t}}}
$$

Where:

$$
\begin{aligned}
& \dot{\mathrm{Q}}_{\mathrm{T}}= \text { Cardiac Output } \\
& \mathrm{V}_{\mathrm{T}}= \text { total volume delivered from the injection syringe determined by } \\
& \text { weighing } \\
& \mathrm{V}_{\mathrm{I}}= \text { volume of injectate in the portion of catheter inside the dog. } \\
& \mathrm{D}_{\mathrm{I}}= \text { density of injectate } \\
& \mathrm{S}_{\mathrm{I}}= \text { specific heat of injectate } \\
& \Delta \mathrm{T}_{\mathrm{I}}= \text { change of temperature between blood and injectate } \\
& D_{\mathrm{B}}=\text { density of blood } \\
& \mathrm{S}_{\mathrm{B}}=\text { specific heat of blood } \\
& \int_{0}^{\infty} \mathrm{T}_{\mathrm{B}} \mathrm{t}_{\mathrm{B}} \mathrm{dt}=\text { area under the temperature time curve in }{ }^{\circ} \mathrm{C} \text { seconds. }
\end{aligned}
$$

The area under the temperature curve is determined by planimetry using a half area method described by Yousof. ${ }^{13}$

\section{Calculation of ETV $_{\mathrm{L}}$}

The product of the thermal dilution cardiac output $\left(\dot{Q}_{\mathrm{T}}\right)$ and the mean transit time for calories to pass through the lungs gives the thermal volume (Figure 2). The product of $\dot{Q}_{\mathbf{T}}$ and the mean transit time for the sodium ions gives the intravascular volume. Subtraction of the intravascular volume from the thermal volume gives the extravascular thermal volume $\left(\mathrm{ETV}_{\mathrm{L}}\right)$. In practice this simplifies to multiplying the difference in mean transit times between calories and sodium ions by the $Q_{\mathrm{T}}$. 


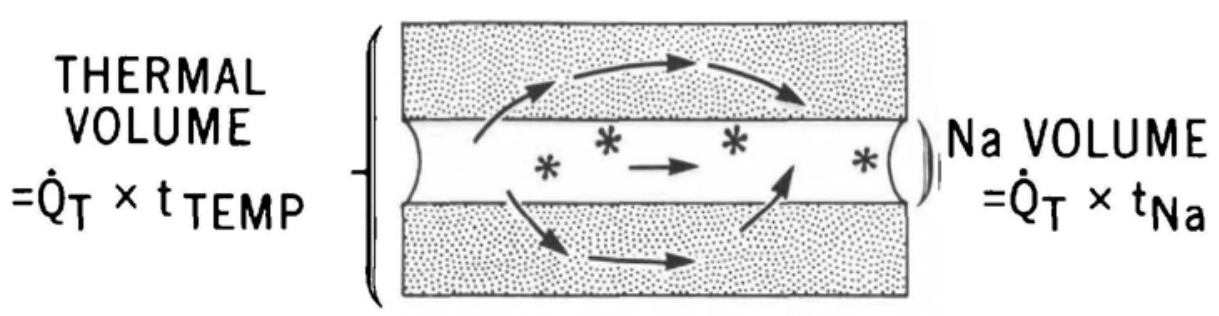

\section{$E T V_{L}=$ THERMAL VOLUME $-\mathrm{Na}$ VOLUME $=\left(\dot{Q}_{T} \times \mathrm{t}_{T} \mathrm{TEMP}\right)-\left(\dot{Q}_{T} \times \mathrm{t}_{\mathrm{Na}}\right)$ $=\dot{Q}_{T}\left(t_{T E M P}-\mathrm{t}_{\mathrm{Na}}\right)$}

Figure 2. Calculation of ETV.

The extravascular indicator is calories $(\uparrow)$ and the intravascular indicator is sodium jons $\left({ }^{\circ}\right)$. $\dot{\mathrm{Q}}_{\mathrm{T}}=$ cardiac output. $\mathrm{T}_{\mathrm{trmp}}=$ Mean transit time for calories. $\mathrm{T}_{\mathrm{Ni}}=$ Mean transit time for sodium ions.

\section{METHODS}

Mongrel dogs weighing 12 to $25 \mathrm{~kg}$ were anaesthetized with pentobarbitone $30 \mathrm{mg} / \mathrm{kg}$. They were intubated and allowed to breathe spontaneously while lying supine. The experimental arrangement is shown diagramatically in Figure 3. Using pressure monitoring, a flexible silastic injection catheter containing a thermistor (Veco) ${ }^{*}$ near its tip was placed in the pulmonary artery through the external juglar vein.

An internal sensing catheter with conductivity electrodes and a thermistor near its tip ${ }^{7}$ was placed just distal to the aortic valve through the left femoral artery.

A catheter was inserted into the right femoral artery so that the hub of the catheter was in direct contact with the skin. Initially we used a short $20 \mathrm{~cm}$ thinwalled catheter. Later, in an attempt to improve our results, we used a long $55 \mathrm{~cm}$ thick walled catheter, Dynetech 5.5 Fr. Polyethylene. An external sensing catheter (Figure 4) similar in construction to the internal catheter but with a connector at the tip and the thermistor extended $10 \mathrm{~cm}$ was attached to the right femoral artery catheter, insulated and strapped to the dog's leg to minimize temperature changes. The extension of the thermistor beyond the comnector ensured that the thermistor was inside the femoral artery catheter and just inside the body. This produced a more stable baseline.

For determination of $\dot{Q}$ and $\mathrm{ETV}_{\mathrm{S}}, 5 \mathrm{ml}$ of 3 per cent sodium chloride was injected rapidly into the pulmonary artery while recording injectate temperature. Blood was withdrawn alternately from the external or internal sensing catheters at a constant rate, so that temperature and conductivity time curves were recorded on a Hewlett Packard 7100 BM recorder. After each determination, blood was reinfused through the femoral vein.

After control measurements were taken, warmed 10 per cent dextran 40 in normal saline was infused to produce an increase in $\mathrm{ETV}_{\mathrm{L}}$ leading to pulmonary oedema.

-Victory Engineering Corp. Springfield, New Jersey. 
P.A. THERMISTOR

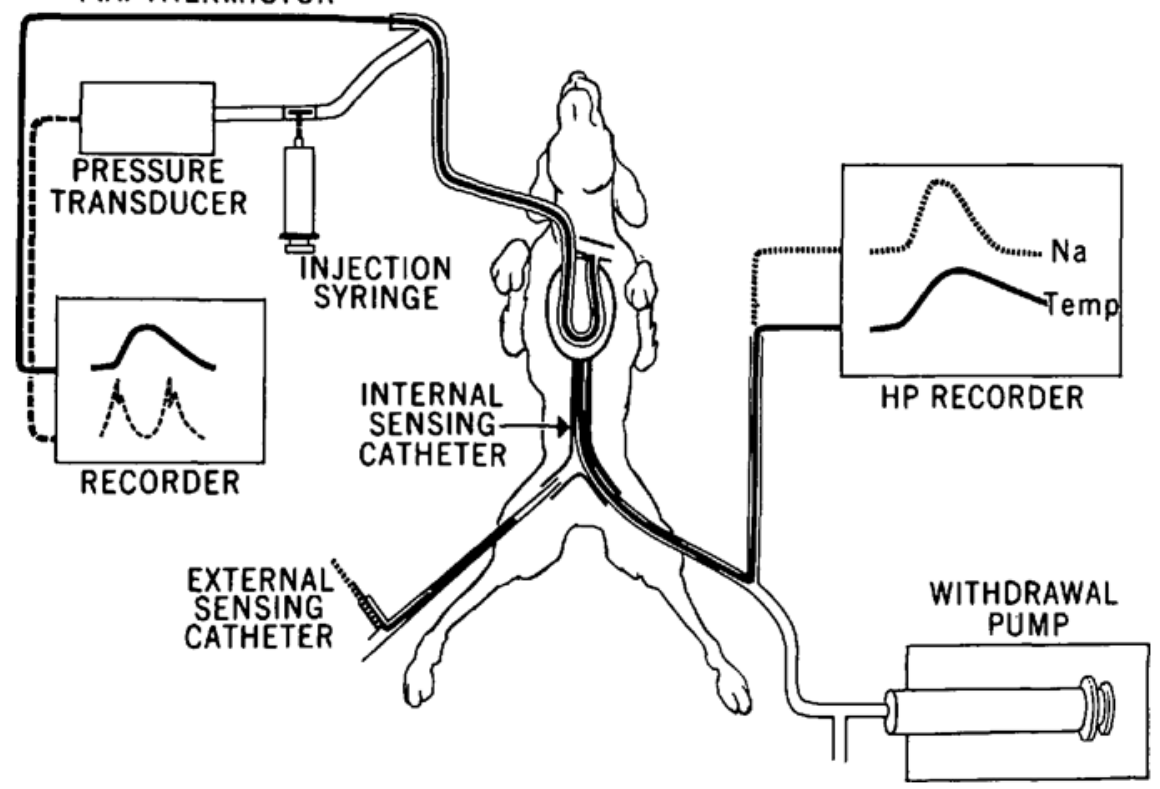

Figure 3. Diagram of The Methods: Indicators are injected into the pulmonary artery and detected by either the internal sensing catheter at a point distal to the aortic valve or the external sensing catheter. The withdrawal pump is shown attached to the internal catheter but in practice a switching arrangement allows withdrawal from either catheter.

The normal range for $\mathrm{ETV}_{\mathrm{L}}$ is 5 to $7 \mathrm{ml} / \mathrm{kg}$. Low values were obtained in two dogs by removing blood.

\section{Results}

With the external sensing catheter connected to the short thin-walled arterial line, 145 comparisons of $\dot{Q}$ and $E_{T}$, measured with the internal and external catheters were obtained in ten dogs. The correlation co-efficient for $\dot{Q}$ was 0.93 , and the mean difference (internal catheter $\dot{\mathrm{Q}}_{\mathrm{T}}$ - external catheter $\dot{\mathrm{Q}}_{\mathrm{T}}$ ) was -0.32 $\pm 0.051 / \mathrm{min}$, a statistically significant difference $(p<0.001)$. The correlation

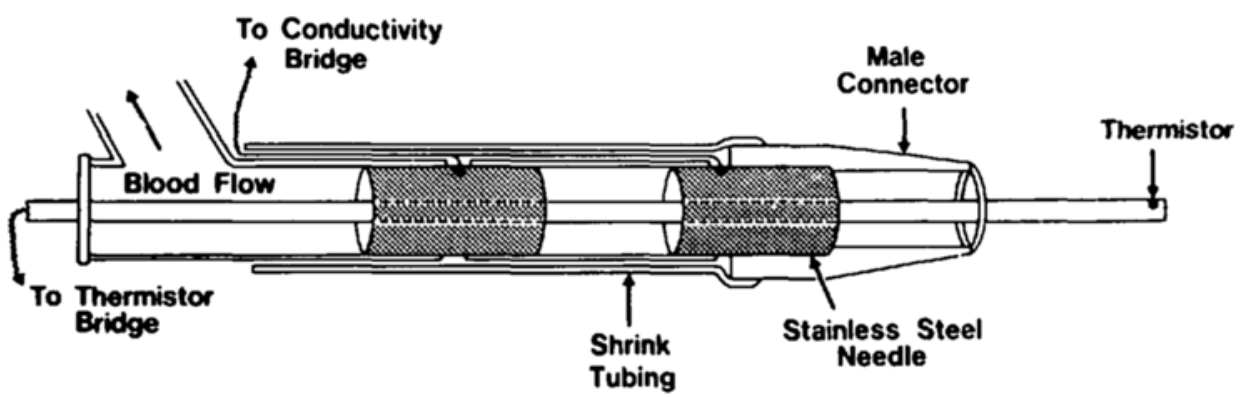

Ficure 4. External sensing catheter with the thermistor extended $10 \mathrm{~cm}$ beyond the tip. 


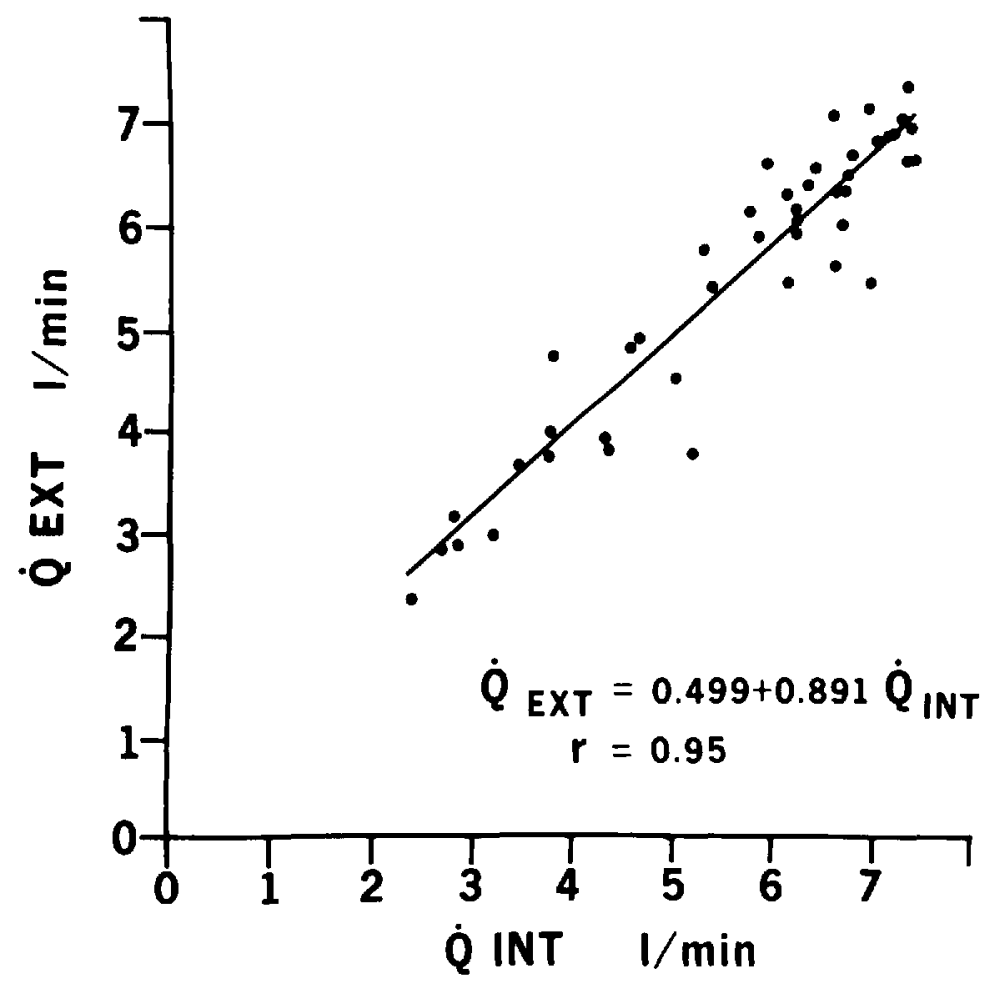

Frcune 5. A comparison of $\dot{Q}$ measured with the internal sensing catheter ( $\dot{Q}$ int) and the external sensing catheter ( $\dot{Q}$ ext). The external sensing catheter was connected to a long thick walled arterial line.

coefficient for $\mathrm{ETV}_{\mathrm{I}}$ was 0.91 and the mean difference (internal catheter $\mathrm{ETV}_{\mathrm{T}_{\mathrm{L}}}$ external catheter $E T V_{L}$ ) was $-2.77 \pm 0.38 \mathrm{ml} / \mathrm{kg}$, a statistically significant difference $(p<0.001)$.

When the external sensing catheter was connected to the long thick-walled arterial line, 45 comparisons of $\dot{Q}_{\mathrm{T}}$ and $\mathrm{ETV}_{\mathrm{L}}$ measured with the internal and external catheters were obtained in two dogs. The correlation for $\dot{Q}_{\mathrm{T}}$ was 0.95 , (Figure 5) and the mean difference (internal catheter $\dot{\mathrm{Q}}_{\mathrm{T}}-$ external catheter $\dot{\mathrm{Q}}_{\mathrm{T}}$ ) was $0.12 \pm 0.07 \mathrm{l} / \mathrm{min}$. This observed difference was not statistically significant $\left(p>0.1\right.$ ). The correlation coefficient for $\mathrm{ETV}_{\mathrm{I}_{\mathrm{L}}}$ was 0.96 (Figure 6 ) and the mean difference (internal catheter $\mathrm{ETV}_{\mathrm{r}}$ - external catheter $\mathrm{ETV}_{\mathrm{L}}$ ) was $-2.46 \pm 0.26$ $\mathrm{ml} / \mathrm{kg}$. a statistically significant difference $(\mathrm{p}<0.001)$. The difference of 2.46 $\mathrm{ml} / \mathrm{kg}$ between internal and external $\mathrm{ETV}_{\mathrm{L}}$ values was consistent throughout the range of $\mathrm{ETV}_{\mathrm{L}}$ values.

\section{Discussion}

Previous dog studies using an internal sensing catheter to detect thermal and conductivity indicators have shown the double indicator dilution technique to be accurate and reliable. ${ }^{\top, 9}$ This study shows a reasonably good agreement between 


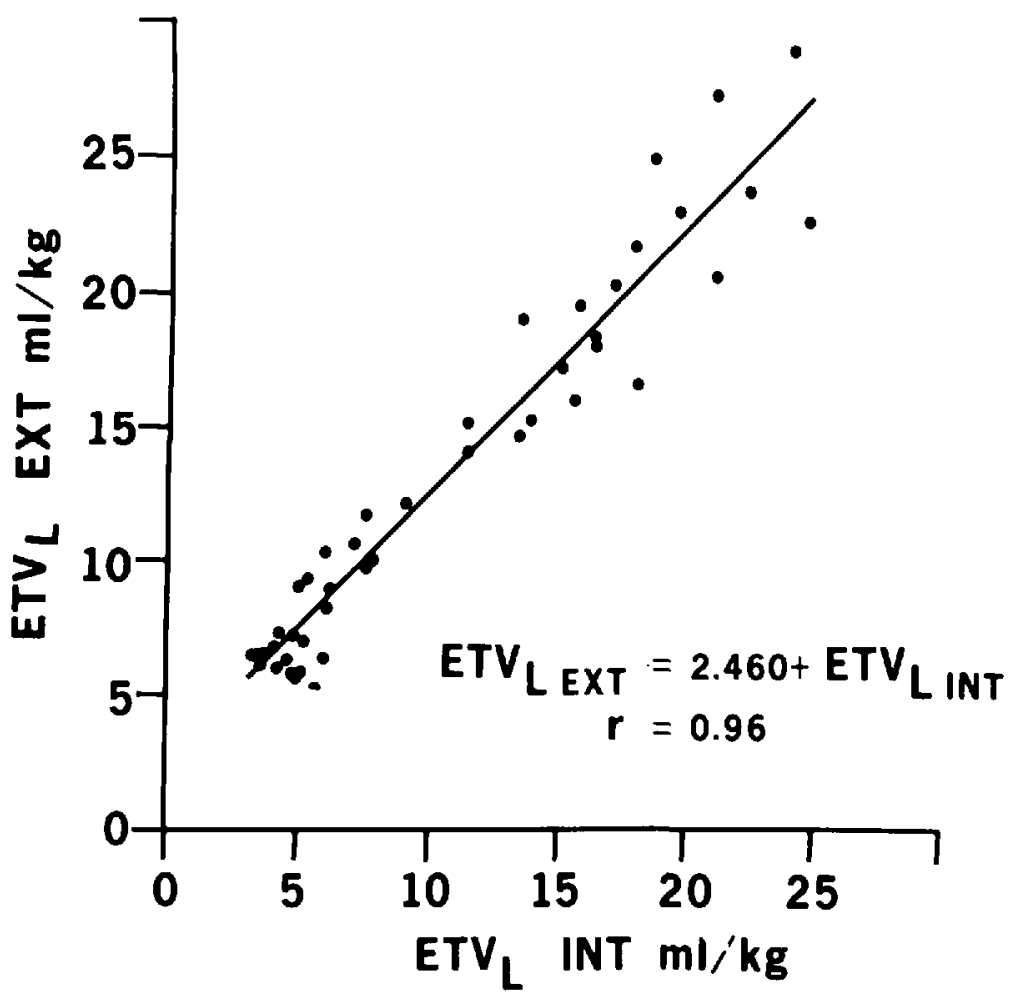

Figure 6. A comparison of $\mathrm{ETV}_{\mathrm{L}}$ measured with the internal sensing catheter (ETV $\mathrm{L}_{\mathrm{t}}$ int) and the external sensing catheter $\left(\operatorname{ETV}_{\mathbf{L}}\right.$ ext). The external sensing catheter was connected to a long thick walled arterial line.

the external catheter technique and the intemal catheter technique of measuring $\dot{Q}$ and ETV $\mathrm{T}_{\mathrm{s}}$ when the external catheter is attached to a $55 \mathrm{~cm}$ long thick-walled, femoral arterial line. With the external catheter attached to a short femoral arterial line $\dot{Q}_{\mathrm{T}}$ and $\mathrm{ETV}_{\mathrm{L}}$ were overestimated by a statistically significant amount. Using a long thick walled catheter, there was no significant difference between the internal and external determinations of $\dot{Q}_{\mathrm{T}}$.

Measurement of $\operatorname{ETV}_{\mathrm{L}}$ requires the detection of an intravascular indicator, sodium, and an extravascular indicator heat. The extravascular indicator is used to determine $\dot{Q}_{\mathrm{T}}$, a factor necessary for the calculation of $\mathrm{ETV}_{\mathrm{L}}$. There should be no loss of indicators between the sites of injection and detection. As calories can cross the vessel wall, introducing the possibility of radial heat exchange, the distance between the sites of injection and detection should be as short as possible. Arfors, ${ }^{14}$ however, concluded that there was no net loss of heat in the pulmonary circulation, and even at very low cardiac outputs net loss of indicator, does not present an obstacle to the use of the thermodilution method for the estimation of $\dot{\mathrm{Q}}_{\mathrm{r}}$. In dogs a comparison of dye dilution and thermal dilution cardiac outputs with the thermal indicator crossing the lungs (correlation coefficient 0.88 ), indicated that there was no significant irreversible loss of heat in the pulmonary vascular bed even in pulmonary oedema. ${ }^{15}$ These results indicate that injection 
into the pulmonary artery and detection in the aorta is satisfactory. In this investigation the higher $\dot{Q}_{\mathrm{T}}$ observed with the short thin walled femoral arterial line may be explained as a result of the system's dimensions, now including the longer pathway to the external catheter, which will tend to increase radial heat exchange resulting in a small loss of indicator and producing too small an area under the thermal dilution curve.

Using the thick-walled catheter we did not observe a significant difference between the internal and external catheter $\dot{Q}_{\mathrm{T}}$. Theoretically this would indicate no loss of indicator in the system and this could be explained by the fact that the long catheter samples blood just distal to the aortic valve and the thick wall with a low thermal conductivity prevents radiant heat exchange down the aorta.

Measurements of $\mathrm{ETV}_{\mathrm{L}}$ require detection of the thermal indicator and an intravascular indicator, sodium. Chinard ${ }^{16}$ and Pearce ${ }^{17}$ found no evidence of sodium leak across the normal lung endothelium in the first passage. Pearce ${ }^{17}$ found a small loss of sodium during one transit in high pressure pulmonary oedema. In a previous study we were not able to detect this loss in pulmonary oedema. ${ }^{9}$ This was also substantiated by comparing ETV $_{\mathrm{T}}$, with post-mortem measurements of pul-

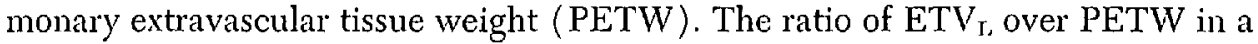
group of dogs with pulmonary oedema was $1.2(\mathrm{~N}=36) .^{7}$

Using the short catheter the mean $\mathrm{ETV}_{\mathrm{L}}$ was overestimated by $2.77 \pm 0.38 \mathrm{ml} / \mathrm{kg}$ and using the long catheter by $2.46 \pm 0.26 \mathrm{ml} / \mathrm{kg}$. These results can be explained in the following way. The calculation of $\mathrm{ETV}_{\mathrm{L}}$ depends upon the $\dot{\mathrm{Q}}_{\mathrm{T}}$ but using the long catheter we did not observe any statistical difference between the internal and external $\dot{Q}_{\mathrm{T}}$. This would tend to indicate that there must be distortion of the curves altering the transit times. Using a long catheter would produce laminar flow and distort the dilution curves, producing a diminution in height and a general prolongation of the curve. The area under the curve would be unaffected but the mean transit time would be prolonged, and it is possible that the thermal curve is more distorted than the conductivity due to some reversible heat exchange with the wall of the catheter. These factors would produce a larger difference between the mean transit times for the thermal and conductivity curves, and overestimate $\mathrm{ETV}_{\mathrm{L}}$. However, the correlation coefficient of 0.96 that we have found indicates a close relationship and the potential for use in clinical situations. Ideally, therefore, to measure $\mathrm{ETV}_{\mathrm{L}}$ an internal sensing catheter should be used. Up to now, however, there have been no reports in the literature of an internal sensing catheter being used in man. If a commercial catheter is not available, and if clinical or pathological circumstances such as narrowing of vessels due to atherosclerosis prevent the insertion of an internal sensing catheter, ETV $\mathrm{I}_{\mathrm{J}}$ measured with an external catheter will yield a result that can be related to the internal $\mathrm{ETV}_{\mathrm{I}}$ value, and can be used for clinical studies.

This technique allows us to determine $\mathrm{ETV}_{\mathrm{L}}$ in patients with long $55 \mathrm{~cm}$ thickwalled indwelling femoral arterial lines and the addition of a Swan-Ganz catheter containing a thermistor.

\section{SUMMARY}

A method for measuring pulmonary oedema $\left(\mathrm{ETV}_{\mathrm{L}}\right)$ is described using sodium ions as the intravascular indicator and heat as the extravascular indicator. The 
technique offers the advantage of virtually unlimited repeatability, relatively uncomplicated instrumentation and no blood loss. There is also the potential for differentiating between pulmonary oedema and pulmonary congestion and determining the efficacy of therapy.

A sensing catheter to detect blood conductivity and temperature changes is required. Ideally the sensing catheter should be situated at a point just distal to the aortic valve. However, a commercially manufactured detecting catheter we had built proved troublesome to insert because of its relatively large diameter. Therefore, an external sensing catheter has been constructed to measure ETV $_{\mathrm{r}}$. and the values obtained have been compared with those from an internal catheter. There was no difference between the internal and external catheter $\dot{\mathrm{Q}}_{\mathrm{T}}$, but $\mathrm{ETV}_{\mathrm{I}}$ was consistently overestimated by $2.46 \pm 0.26 \mathrm{ml} / \mathrm{kg}$. However, this value can be related to the internal value and can be used for clinical studies.

\section{RÉSUMÉ}

La mesure de l'eau pulmonaire extra-vasculaire $\left(E_{T} V_{L}\right)$ s'est butée jusqu'ici à des difficultés techniques qui la rendaient à peu près impraticable. En cherchant des indicateurs plus maniables que les isotopes, Pearce et Beazell ont proposé d'utiliser la chaleur qui en l'occurence se comporte comme un indicateur non moléculaire diffusible. Noble et Severinghaus utilisent une solution de $\mathrm{NaCl}$ à 3 pour cent à la température de la pièce: la diffusion thermique sert d'indicateur extra-vasculaire et les ions sodium d'indicateur intra-vasculaire. Ce travail décrit l'emploi de ces indicateurs pour mesurer l'ETV $\mathrm{L}_{\mathrm{L}}$. La technique nécessite des instruments relativement simples, n'entraine pas de perte de sang et est virtuellement répétable à satiété.

Il faut disposer d'un cathéter capteur capable de percevoir des changements de la conductivité du sang et de sa température. De façon idéale, ce capteur se place dans l'aorte, tout près de la valve aortique. Cependant, celui qu'on nous avait fabriqué, s'est avéré impraticable à cause de sa taille et aussi nous en avons conçu un autre pour usage externe. Les mesures de $\operatorname{ETV}_{\mathrm{L}}$ et de débit cardiaque par diffusion thermique ( $Q_{\mathrm{I}}$ ), obtenues par l'un et l'autre cathéter ont été comparées: les $\mathrm{Q}_{\mathrm{T}}$ étaient tout à fait comparables d'un cathéter à l'autre mais l'ETV $\mathrm{T}$ était constamment surestimé par le capteur externe. Cependant, l'information recueillie par ce capteur extrene peut être redressée et utilisée cliniquement.

\section{ACKNOWLEDGMENTS}

We wish to thank Mrs. N. Bell, Mr. G. Carmichael, and Mr. G. Caskanette for their technical assistance, Miss C. Mindorff for help with the manuscript, and the Departments of Medical Art and Medical Photography at St. Michael's Hospital.

We thank Abbott Labs. Ltd. for supplying the Nembutal.

This work was supported by Canadian Thoracic and Respiratory Disease Assoc. Grant number 3-333-269-30. 


\section{REFERENCES}

1. Visscher, M.B., HADDy, F.J., \& Stephens, G. The physiology and pharmacology of lung edema. Phamacol. Rev. 8: 389 (1956).

2. Noble, W.H. \& Sieniewicz, D.J. Radiological changes in controlled hypervolaemic pulmonary oedema in dogs. Can. Anaes. Soc. J. 22: 171 (1975).

3. Chinamd, F.P. \& Enns, T. Transcapillary pulmonary exchange of water in the dog. Am. J. Physiol. 178: 197 (1954).

4. Gump, F.E., Mashima, Y., \& Krnney, J.M. Water balance and extravascular lung water measurements in surgical patients. An. J. Surg. 119: 515 (1970).

5. McCnedie, M. Measurement of pulmonary edema in valvular heart disease. Circulation 36: 381 (1967).

6. Van De Water, J.M., Sheh, J., O'Connor, N.E., Millar, I.T., \& Milne, E. Pulmonary extravascular water volume: measurement and significance in critically ill patients. J. Trauma 10: 440 (1970).

7. Noble, W.H. \& Severinghaus, J.W. Thermal and conductivity curves for rapid quantitation of pulmonary edema. J. Appl. Physiol. 32(6): 770 (1972).

8. Pearce, M.L. \& Beazell, J.W. The measurement of pulmonary parenchymal volume by themal indicator dilution (Abstract). Clinical Res. 14: 182 (1966).

9. Noble, W.H., Obdrzalek, J., \& Kax, J.C. A new technique for measuring pulmonary edema. J. Appl. Physiol. 34(4): 508 ( 1973).

10. Anderson, W.P., Dunegan, L.J., Knight, D.C., Fitzpatrick, G.F., O’Connor, N.E., \& Morgan, A.P. Rapid estimation of pulmonary extravascular water with an instream catheter. J. Appl. Physiol. 39( 5): 843 (1975).

11. Dunegan, L.J., Knight, D.C., Harken, A., O'Connor, N., \& Morgan, A. Lung themal volume in pulmonary edema. Ann. Surg. $181: 809$ (1975).

12. Noble, W.H., Kovacs, K., \& KAY, J.C. Fine structural changes in hemodynamic pulmonary edema. Can. Anaesth. Soc. J. 21: 275 (1974).

13. Yousor, A.M., ENinus, J., \& Bicik, V. Simple method of measuring dye curve area by planimetry using the half-area method. J. Appl. Physiol. 36(5): 61 I (1974).

14. Arfons, K.E., Maimberg, P., \& Pavek, K. Conservation of thermal indicator in lung circulation. Cardiovascular Res. 5: 530 (1971).

15. KAY, J.C. \& Noble, W.H. A comparison of thermal and dye dilution methods of determining cardiac output. Can. Anaesth. Soc. J. 20:347 (1973).

16. Chinalid, F.P. The permeability characteristics of the pulmonary blood gas barrier. Advances in Respiratory Physiology, edited by C.G. Caro. London: Amold 106 (1966).

17. Pearce, M.L. Sodium recovery from normal and edematous lungs studied by indicator dilution curves. Circ. Res. 24: 815 ( 1969$)$. 